\title{
A study of sensorless vector control of IM using neural network luenberger observer
}

\author{
Tahar Belbekri, Bousmaha Bouchiba, Ismail Khalil Bousserhane, Houcine Becheri \\ Department of Electrical Engineering, Tahri Mohamed University Béchar, Algeria
}

\begin{tabular}{l}
\hline \hline Article Info \\
\hline Article history: \\
Received Oct 26, 2019 \\
Revised Feb 15, 2020 \\
Accepted May 4, 2020 \\
\hline
\end{tabular}

Keywords:

Artificial intelligence

Asynchronous motor

Luenberger

Neural network

Vector control

\begin{abstract}
After the development of electronic components, the elimination of the sensors has become a necessary subject to get good results in the field of speed control, because of the price of the sensors, the strenuous choice of its position and the disturbance of measurement which affects the robustness of control. The luenberger observer showed to be one of the most excellent methods suggested by the researchers; this is due to the best performance, it offers in terms of stability, reliability and less counting effort. In this article, a study of luenberger observer based on neural network-based was discussed. This artificial intelligence method makes it possible to decrease the error of estimated speed for IRFOC control of the induction motor. Simulation results are obtained to show the robustness and stability of the system.
\end{abstract}

This is an open access article under the $\underline{C C B Y-S A}$ license.

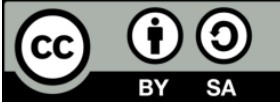

\section{Corresponding Author:}

Tahar Belbekri,

Department of Electrical Engineering,

Tahri Mohamed University,

Mohammed Tahri University Béchar, B.P 417, Kenadsa road. 08000 Béchar, Algeria.

Email: taharmoh87@yahoo.fr

\section{INTRODUCTION}

Owing to the advance of power electronics in latest years, the control of variable speed motors has increased notably. The asynchronous motor is the most utilized in the engineering field because of its robustness, low price and simplicity of usage maintenance. But it has a difficult, its control is not simple because of stator field and the rotor current is not measurable without intermediary $[1,2]$.

The FOC is founded on efficient control of the magnetic variable. It has been in latest years the essential research way and better adapted to industrial exigency. However, this configuration requires, in general, the installment of sensor on the rotor for the knowing of a mechanical measure [3]. The goal of this control is to be able to command the asynchronous motor as a direct current motor with separate excitation where there is a normal decoupling among the flux quantity, the excitation current, and that associated to the torque, the stator current. This decoupling renders it possible to have a so rapid torque response $[4,5]$.

The problematic of our paper is to eliminate the speed sensor and change it with another technique to obtain its value. In our study, we chose vector control by orientation of the rotor flow which requires the installment of a sensor to measure the speed or position of the rotor flow. The integration of this sensor boosts the mass and the price which can be big than that of the motor for the low power. It is too essential to reserve a supplementary location for the installment of the sensor. But that is not constantly wanted or available. Lastly, the reliability of the structure reduces because of this crisp instrument that needs particular attention for itself and for its association. It is from these remarks that the idea of removing the speed sensor was born. To solve this problematic, several studies have concentrated in the last few years on the developing of diverse approaches to estimate speed. For that purpose, removing a speed sensor in the IRFOC makes use 
of its evaluation from the electrical variables of the stator (voltage, current) [6, 7]. In the observers, we select the luenberger observer, which offers the possibility of reconstructing the states of an observable structure from the quantities of inputs and outputs. It's used in state feedback controls when all or part of the variable cannot be evaluated. This estimator can be utilized, for example to obtain the flux of the motor knowledge that these measures are far from being simply determinate [8].

The goal of our paper is to ameliorate the results attained by the luenberger observer which is based on the PI regulator. For this, we chose to use artificial intelligence techniques. In in our last published article, we applied the fuzzy technique, and we founded good results compared to the old techniques. For the same reasons, we decided to apply another method of artificial intelligence in this article.

Neural network is one of the techniques of artificial intelligence, this technique has proved their effectiveness in several areas: such as signal processing, parametric identification, control of non-linear processes, estimation and fault detection $[19,24,25]$.

In our paper, we will utilize the neural network to upgrade the estimation of speed and to obtain a great performance and effective control. This article is structured like this. Section 2 presents the induction motor model. Section 3 describes the technique of the indirect vector control. Section 4 discusses the luenberger observer and his structure. The next section describes the luenberger observer technique connected to neural network. The results of simulation and discussion are offered in section 6 and 7 , respectively. The last section presents the conclusion of the article.

\section{THE MODEL OF INDUCTION MOTOR}

The modeling of the asynchronous motor is founded on the Park conversion, which connects the rotor and stator electrical states equations to perpendicular axes, electrically termed d (direct), and q, (quadrature).

The induction machine can be defined by next states equations in the circling field's reference framework $[9,16]$.

$$
\left\{\begin{array}{l}
\dot{X}=A \cdot X+B \cdot U \\
Y=C \cdot X
\end{array}\right.
$$

With:

$$
\begin{aligned}
A & =\left[\begin{array}{cccc}
-a_{1} & w_{s} & a_{2} & a_{3} \cdot w_{r} \\
-w_{s} & -a_{1} & -a_{3} \cdot w_{r} & a_{2} \\
a_{4} & 0 & -a_{5} & \left(w_{s}-w_{r}\right) \\
0 & a_{4} & -\left(w_{s}-w_{r}\right) & -a_{5}
\end{array}\right] ; B=\left[\begin{array}{cc}
\frac{1}{\sigma L_{s}} & 0 \\
0 & \frac{1}{\sigma L_{s}} \\
0 & 0 \\
0 & 0
\end{array}\right] ; X=\left[\begin{array}{l}
i_{\alpha s} \\
i_{\beta s} \\
\phi_{\alpha r} \\
\phi_{\beta r}
\end{array}\right] ; U=\left[\begin{array}{c}
V_{\alpha s} \\
V_{\beta s}
\end{array}\right] \\
Y & =\left[\begin{array}{c}
i_{\alpha s} \\
i_{\beta s}
\end{array}\right] ; C=\left[\begin{array}{l}
1000 \\
0100
\end{array}\right] .
\end{aligned}
$$

And:

$$
T_{r}=\frac{L_{r}}{R_{r}}, a_{1}=\frac{R_{s}}{\sigma L_{s}}+\frac{R_{r} L_{m}^{2}}{\sigma L_{s} L_{r}^{2}}, a_{2}=\frac{L_{m}}{\sigma L_{s} L_{r} T_{r}}, a_{3}=\frac{L_{m}}{\sigma L_{s} L_{r}}, a_{4}=\frac{L_{m}}{T_{r}}, a_{5}=\frac{1}{T_{r}} .
$$

\section{INDIRECT FIELD-ORIENTED CONTROL}

The independent excitation direct current motor is very adapted for torque control, because it just necessities to controller its induced current. The objective is to make the similar thing with the asynchronous motor. This is exactly the of the vector control [11].

In IRFOC, the flux is not controlled; so, the flow sensors are not required in the estimators and observers, but the quantity of the rotor locality is needed. This method is very simple but evidently his performance is lower than to the RFOC, this is owing to the sensibility of this genre of control to the change of the rotor time constant. The benefit of this technique is to utilize just reference measurement which by definition is not disturbed. In effect, from an electromagnetic situation torque $C_{e m}^{*}$ and the reference rotor flow $\varphi_{d r}^{*}$, the reference currents $i_{d s}^{*}$ and $i_{q s}^{*}$ can be assumed directly from the state equations.

$$
i_{d s}^{*}=\frac{1}{L_{m}} \cdot\left(\tau_{r} \cdot \dot{\varphi}_{d r}^{*}+\varphi_{d r}\right)
$$




$$
i_{q s}^{*}=\frac{L_{r}}{P \cdot L_{m}} \cdot \frac{C_{e m}}{\varphi_{d r}^{*}}
$$

The IRFOC technique is based on the generation of the supply voltages in order to find a wanted flow and torque.

By using the voltage supply of the asynchronous machine, the control states are the voltage $v_{d s}$ and $v_{q s}$.

$$
\begin{aligned}
& v_{d s}=R_{s} \cdot i_{d s}+\sigma \cdot L_{s} \cdot \frac{d i_{d s}}{d t}+\frac{L_{m}}{L_{r}} \cdot \frac{d \phi_{r}}{d t}-\sigma \cdot L_{s} \cdot \omega_{s} \cdot i_{q s} \\
& v_{q s}=R_{s} \cdot i_{q s}+\sigma \cdot L_{s} \cdot \frac{d i_{q s}}{d t}+\omega_{r} \cdot \frac{L_{m}}{L_{r}} \cdot \phi_{r}+\omega_{s} \cdot \sigma \cdot L_{s} \cdot i_{d s}
\end{aligned}
$$

The Coupling is among the two states $\left(v_{d s}, v_{q s}\right)$, can be averted by utilizing many compensation methods [10].

\subsection{Decoupling by conventional compensation}

This technique consists in adaptation of the currents by elimination of the conjunction variables. These are toted to the output of the current regulators to find the reference voltages required for the regulation (figure 1). The supplementary terms are fixed in which the residual voltages are related with the corresponding currents [10].

The expression of the voltages at the output of correctors is:

$$
\begin{aligned}
& v_{d s}^{r}=R_{s} i_{d s}+\sigma \cdot L_{s} \cdot \frac{d i_{d s}}{d t} \\
& v_{q s}^{r}=R_{s} \cdot i_{q s}+\sigma \cdot L_{s} \cdot \frac{d i_{q s}}{d t}
\end{aligned}
$$

The expression of the coupling voltages are:

$$
\begin{aligned}
& v_{d s}^{c}=\frac{L_{m}}{L_{r}} \frac{d \phi_{r}}{d t}-\sigma \cdot L_{s} \cdot \omega_{s} \cdot i_{q s} \\
& v_{q s}^{c}=\omega_{s} \cdot \frac{L_{m}}{L_{r}} \cdot \phi_{r}+\sigma \cdot L_{s} \cdot \omega_{s} \cdot i_{d s}
\end{aligned}
$$

The term $\frac{L_{m}}{L_{r}} \frac{d \phi_{r}}{d t}$ is equals zero, seeing the stable state. Therefore, the reference voltages desired for the control:

$$
\begin{aligned}
& v_{d s}^{*}=v_{d s}^{c}+v_{d s}^{r} \\
& v_{q s}^{*}=v_{q s}^{c}+v_{q s}^{r}
\end{aligned}
$$

The pulsation $\omega_{s}^{*}$ is essential for the opposite conversion of park in order, to obtain the real reference voltages, is found by the next equation:

$$
\omega_{s}^{*}=\omega_{r}+\frac{L_{m} R_{r}}{L_{r} \phi_{r}} i_{q s}
$$




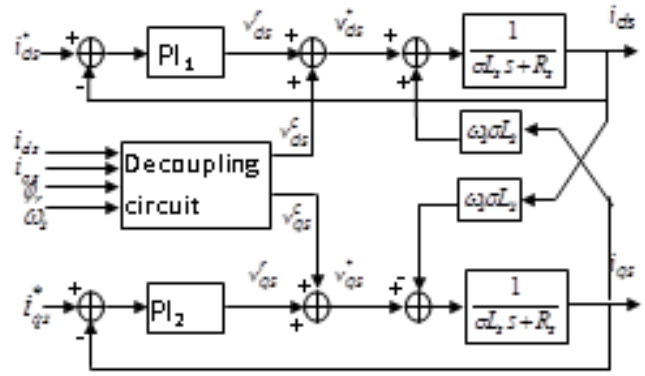

Figure 1. Decoupling by classic compensation

The graphic diagram of the speed control of the asynchronous motor by the IRFOC technique is given in figure 2 .

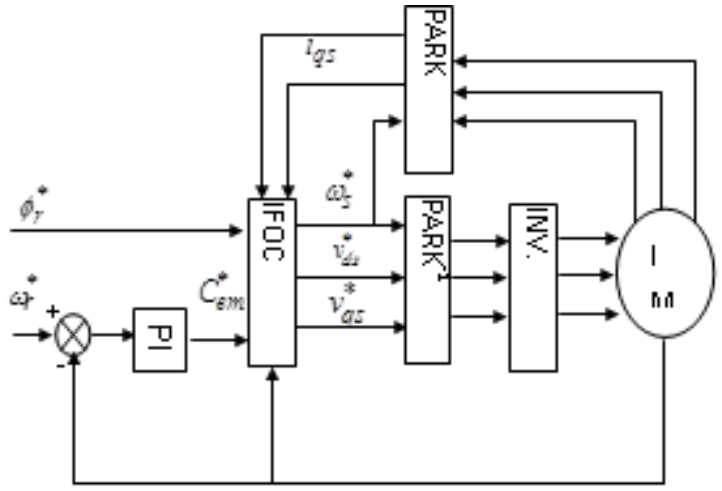

Figure 2. Diagram of the IRFOC of induction motor

\subsection{Rotor speed controller}

The speed controller gives the reference torque, a goal of preserving the corresponding speed. For the technique to be justified, it is essential that the internal loop is so rapid than the loop of the speed. The mechanical expression is:

$$
\frac{\omega_{r}}{C_{e m}}=\frac{P}{f_{c}+J \cdot s}
$$

The closed loop transfer function is given by:

$$
\frac{\omega_{r}}{\omega_{r}^{*}}=\frac{\left(K_{p \omega} \cdot s+K_{i \omega}\right) \frac{P}{J}}{\rho(s)}
$$

The controller PI parameters is given by: $[10,11]$

$$
\left\{\begin{array}{l}
K_{i}=\frac{2 \cdot J \cdot \rho_{\omega}^{2}}{P} \\
K_{p}=\frac{2 \cdot \rho_{\omega} \cdot J-f_{c}}{P}
\end{array}\right.
$$




\section{LUENBERGER OBSERVER} $[12]$.

This type is one of the deterministic observers which belong to the group of closed loop observers

\subsection{Design of Luenberger observer}

The next figure represents the schematic diagram of luenberger observer

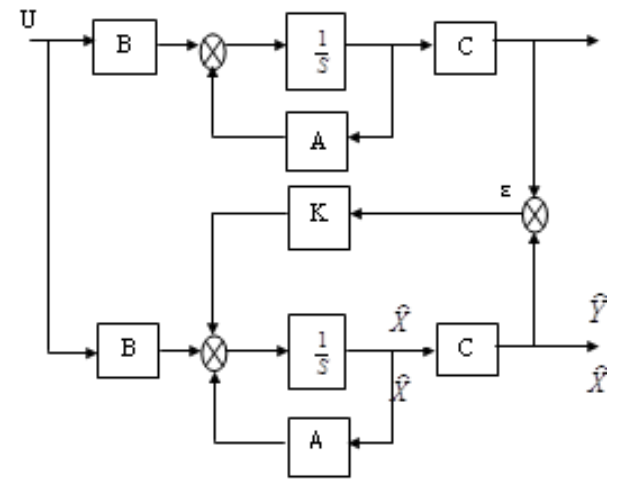

Figure 3. Schematic diagram of Luenberger observer

The estimated states are represented by the circumflex accent and $\mathrm{k}$ is the gain of the observer, his state model is given by: $[5,6,8]$.

$$
\left\{\begin{array}{l}
\hat{\dot{X}}=\hat{A} \cdot \hat{X}+B \cdot U+K \cdot(Y-\widehat{Y}) \\
\widehat{Y}=C \cdot \hat{X}
\end{array}\right.
$$

With:

$$
\hat{X}=\left[\begin{array}{l}
\hat{i}_{\alpha s} \\
\hat{i}_{\beta s} \\
\hat{\phi}_{\alpha r} \\
\hat{\phi}_{\beta r}
\end{array}\right], \hat{Y}=\left[\begin{array}{l}
\hat{i}_{\alpha s} \\
\hat{i}_{\beta s}
\end{array}\right], K=\left[\begin{array}{cc}
K_{1} & -K_{2} \\
K_{2} & K_{1} \\
K_{3} & -K_{4} \\
K_{4} & K_{3}
\end{array}\right] \hat{A}=\left[\begin{array}{cccc}
-a_{1} & 0 & a_{2} & a_{3} \cdot \widehat{w}_{r} \\
0 & -a_{1} & -a_{3} \cdot \widehat{w}_{r} & a_{2} \\
a_{4} & 0 & -a_{5} & -\hat{w}_{r} \\
0 & a_{4} & \hat{w}_{r} & -a_{5}
\end{array}\right]
$$

We will use the pole placement methods and the Lyapunov approach to calculate the observer gain

$$
\left\{\begin{array}{l}
K_{1}=-(k-1) \cdot\left(\frac{1}{\sigma T_{s}}+\frac{1}{\sigma T_{r}}\right) \\
K_{2}=(k-1) \cdot \widehat{w}_{r} \\
K_{3}=\left(k^{2}-1\right) \cdot\left[\left(\frac{1}{\sigma T_{s}}+\frac{1-\sigma}{\sigma T_{r}}\right) \frac{\sigma L_{s} L_{m}}{L_{r}}+\frac{L_{m}}{T_{r}}\right] \\
\frac{\sigma L_{s} L_{m}}{L_{r}}(k-1)\left(\frac{1}{\sigma T_{s}}+\frac{1-\sigma}{\sigma T_{r}}\right) \\
K_{4}=(k-1) \cdot \frac{L_{s} L_{m}}{L_{r}} \cdot \widehat{w}_{r}
\end{array}\right.
$$

The poles of the observer are chosen to have a rapid convergence to the dynamics of the open-loop system. The gain $\mathrm{K}$ is generally selected small [12, 14, 15, 23]. 


\subsection{Adaptation mechanism of Luenberger}

The objective of this section is to look for an adaptation law to estimate the speed. We use Lyapunov theory to reduce the adaptive speed mechanism.

This observer is constituted by the estimation error on the stator current and the rotor flux. The difference between this observer and the MAS model is described by:

$$
\dot{e}=(A-K C) e+(\Delta A) \hat{X}
$$

With:

$$
\Delta A=A\left(w_{r}\right)-A\left(\widehat{w}_{r}\right)=\left[\begin{array}{cccc}
0 & 0 & 0 & a_{3} \cdot \Delta w_{r} \\
0 & 0 & -a_{3} \cdot \Delta w_{r} & 0 \\
0 & 0 & -a_{5} & -\Delta w_{r} \\
0 & 0 & \Delta w_{r} & -a_{5}
\end{array}\right]
$$

we give the law of adaptation of the estimated speed: [10, 12, 13].

$$
\widehat{w}_{r}=\lambda a_{3} \int_{0}^{t}\left(e_{i_{\alpha s}} \widehat{\phi}_{\beta r}-e_{i_{\beta s}} \widehat{\phi}_{\alpha r}\right) d t
$$

by using of PI controller, the estimated speed is given by $[14,15]$.

$$
\widehat{w}_{r}=k_{p}\left(e_{i_{\alpha s}} \widehat{\phi}_{\beta r}-e_{i_{\beta s}} \widehat{\phi}_{\alpha r}\right)+k_{i} \int\left(e_{i_{\alpha s}} \widehat{\phi}_{\beta r}-e_{i_{\beta s}} \widehat{\phi}_{\alpha r}\right) d t
$$

With:

$k_{p}$ and $k_{i}$ : positives constants [23].

\section{NEURAL NETWORK LUENBERGER OBSERVER}

Artificial neural networks (ANNs) are a group of measurable learning algorithms which use the data to learn for a purpose of calculating values from the inputs [17].

The result of scientific works gives a lot of cases of succeeded control executions utilizing neural systems. The big problem on this way is the decision of a suitable neural system design for use in the control. However, some control structures are firmly identified with their neuronal partners, which encourages neuronal usage $[18,19,20]$.

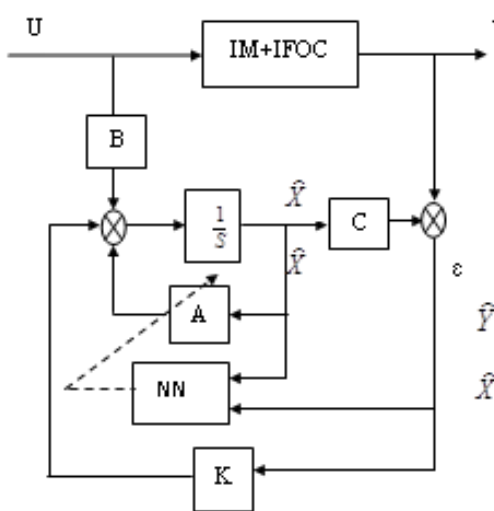

(a)

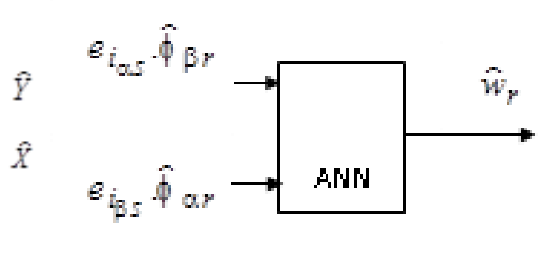

(b)

Figure 4, (a) Block diagram of neural network luenberger observer, (b) Block diagram of neural network 
As the simulation results will show, Figures 4 shows the schematic diagram of the learning of speed by neural networks learning offline. The output of the induction motor plays the role of the supervisor and provides the desired information. This information is compared with the output of the observer developed by the neural network. The adaptation algorithm uses the error generated to adjust the weights of the neural network [21, 22].

\section{RESULTS AND DISCUSSION}

In this section, we use Matlab software to show the simulation of sensorless indirect vector control using the luenberger observer with an adaptation mechanism based on the neural network technique.

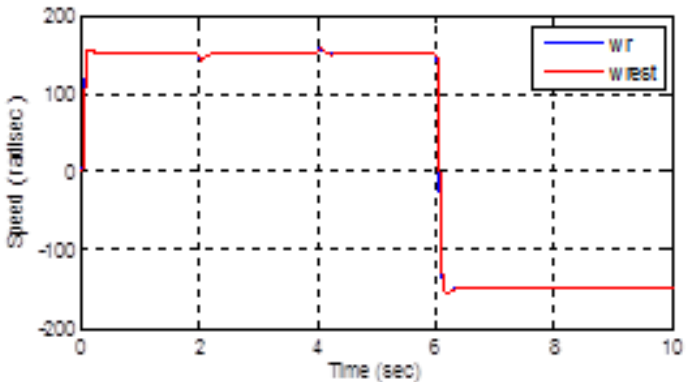

(a)

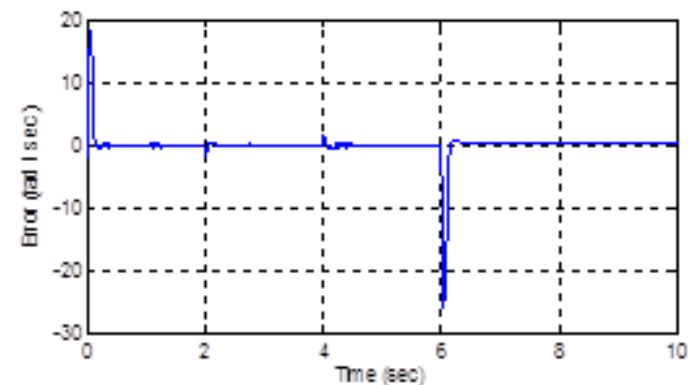

(b)

Figure 5, (a) Estimated and actual speed response with Luenberger observer, (b) Error of estimated and actual speed response

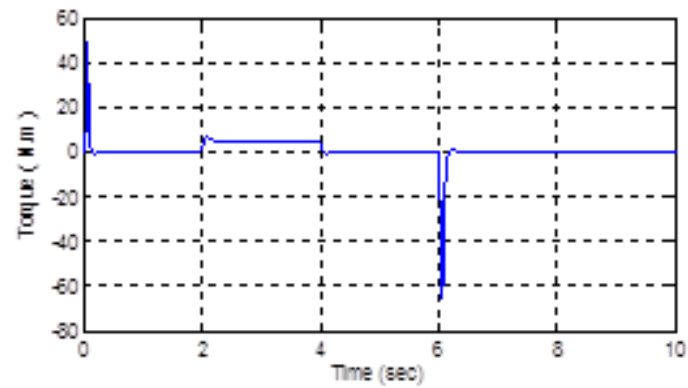

Figure 6, Torque of IRFOC

After using the neural network technique in the luenberger observer, we notice that the results obtained are great and improved compared to the previous researches.

The simulation results shown in Figures 5 and 6 present the comparison among estimated and real speed by using Neural network luenberger observer, we applied 10 N.m load disturbance at t equals to 2 and $4 \mathrm{sec}$ respectively.

The control of motor by using the sensor or the estimator gives the same dynamic performance even if torque resistant is applied.

An estimation error of 19 ( $\mathrm{rad} / \mathrm{sec})$ was obtained at the starting, and decreases to a value near to 0 at the time $t=0.3 \mathrm{sec}$, it gives an overshoot of $12.66 \%$. The command was able to reject the load coupler. When the speed reference has been inverted, the estimation error value changes to $-26(\mathrm{rad} / \mathrm{sec})$ and decreases to a value near to 0 after $6.4 \mathrm{sec}$.

At the time of starting, the torque increases rapidly to the value of $51.12 \mathrm{~N} . \mathrm{m}$, and quickly returns to its initial value; afterward it follows the trajectory of the resistant torque. When reversing the speed, it decreases to the value of - $64 \mathrm{Nm}$ and returns to its original value

In all the results, we have a significant estimation of the speed. The estimated speed follows perfectly the trajectories of the references; the estimated error of speed rapidly converges to the null value. 


\section{CONCLUSION}

In this article, we have made a theoretical study of the indirect vector control, without the speed sensor of the induction motor by the use of the speed estimation technique, which based on the luenberger observer with an adaptation mechanism developed by integration of the neural network technique. the results were obtained by a simulation software.

By using the neural network Luenberger observer, the simulation results comparison of estimated and actual speed response, for different operating regimes of the machine allows us to confirm the best performances offered, faster response with a minimized overrun during start up and speed reversal. Obtaining high performance with an asynchronous machine necessitates complex commands, which require in particular the knowledge of the parameters and the rotor states.

Generally, this study has shown very effective control and satisfying for the industrial needs, because of the minimization of the estimation error on the one hand, the robustness and the stability of the system in operation under any conditions of use on the other hand.

\section{ACKNOWLEDGEMENTS} comments.

We are grateful to all the reviewers for their careful reading of the paper and their helpful

\section{REFERENCES}

[1] R. Mini, C. Saranya, B. H. Satheesh, M. N. Dinesh, "Low speed estimation in sensorless direct torque controlled induction motor drive using extended kalman filter," International Journal of Power Electronics and Drive System (IJPEDS), vol. 6, no. 4, pp. 819-830, 2018.

[2] H. Nayeem, H. Iqbal "A Luenberger-Sliding Mode Observer for Online Parameter Estimation and Adaptation in High-Performance Induction Motor Drives," Transactions on Industry Applications, Vol. 45, no. 2, pp. 772-781 2009.

[3] M. Benamour, "Control by DTC of the induction machine without sensor. Use of KALMAN filter for speed estimation," thesis of Magister, Mustapha Benboulaïd, Batna (Algeria), 2012.

[4] P. J. Shaija, D. Asha Elizabeth "An intelligent speed controller design for indirect vector controlled induction motor drive systeme," Procedia technology Science direct, vol 25, pp. 801-807 2016.

[5] Y. Beddiyaf, "Study and Simulation of estimators and robust observers of flux and speed for the asynchronous machine," thesis of Magister, Mustapha Benboulaï, Batna, 2016.

[6] S. DAMKHI, "Sensorless speed control of induction motor by the SIGNAL FLOW GRAPHS (SFG) of HOLTZ," thesis of Magister, Mustapha Benboulaïd, 2007.

[7] H. Nayeem, H. Iqbal, "Robust sensorless vector control of an induction machine using multiobjective adaptative fuzzy luenberger observer," ISA Transactions Elsevier, Vol. 74, pp. 144-154, 2018.

[8] A. Chebbi, "Backstepping command of a machine asynchronous without speed sensor," thesis of Magister, Mustapha Benboulaïd, Batna, 2011.

[9] S. Maiti, C. Chakraborty, "A new instantaneous reactive power based MRAS for sensorless induction motor drive," Simulation modelling practice and theory, vol. 18, pp. 1314-1326, 2010.

[10] I. K. Bousserhane, "Fuzzy Controllers Optimized by the Genetic Algorithm for Controlling an Asynchronous Machine,", Doctoral thesis, USTO, 2008.

[11] B. Bouchiba, A. Hazzab, H. Glaoui, M. K. Fellah, I. K. Bousserhane, P. Sicard, "Backstepping control for multimachine web winding system," Journal of electrical engineering and technology, vol. 6, no. 1, pp. 59-66, 2011.

[12] D. Cherifi, Y. Miloud, A. Tahri, "Simultaneous estimation of rotor speed and stator resistance in sensorless indirect vector control of induction motor drives using a luenberger observer," International Journal of computer science issues, vol. 9, no. 2, pp. 325-335, 2012.

[13] M. Jouili, M. Jarray, Y. Koubaa, M. Boussak, "A Lunberger state observer for simultaneous estimation speed and rotor resistance in sensorless indirect stator flux orientation control of induction motor drive", International journal of computer science issues, Vol. 8, no. 3, pp. 116-125, 2011.

[14] M. Messaoudi, L. Sbita, M. Benhamed, H. Kraiem, "MRAS and luenberger observer based sensorless vector control of induction motors", Asian journal of information technology, vol. 6, no. 4, pp. 232-239, 2008.

[15] A. Bennassar, A. Abbou, A. Akheraz, M. Barara, "Sensorless sliding mode control of induction motor based on luenberger observer using fuzzy logic adaptation mechanism," Journal of theoretical and applied information technology, vol. 65, no. 1, pp. 130-136, 2014.

[16] C. Ben regaya, C. Zaafouri, A. Chaari, "Electric drive control with rotor resistance and rotor speed observers based on fuzzy logic," Mathematical Problems in Engineering, pp. 1-9, 2014.

[17] M. Zolfaghari, T. Seyed abbas, D. Vindel munuz, M. Barara, "Neural network-based sensorless direct power control of permanent magnet synchronous motor," Ain shams engineering journal, vol. 7, pp. 729-740, 2016.

[18] A. Medvedev, G. Hillerstrom, "Periodic disturbance rejection: A neural network approach," Springer-Verlag London Limited, pp. 814-817, 1993. 
[19] J. Ghouili, "Sensorless control of an asynchronous machine with Esti- ming speed by neural network", Doctoral thesis, Québec University, (2005).

[20] N. Thuy Pham, D. Phu Nguyen, K. Huu Nguyen, N. Van Nguyen "New Version of Adaptive Speed Observer based on Neural Network for SPIM,", International Journal of Power Electronics and Drive System (IJPEDS), Vol. 9, No. 4, pp. 1486-1502, 2018.

[21] A. Mishra, P. Choudhary "Artificial Neural Network Based Controller for Speed Control of an Induction Motor using Indirect Vector Control Method," International Journal of Power Electronics and Drive System (IJPEDS), Vol. 2, No. 4, pp. 402-408, 2012.

[22] B. Purwahyudi, Soebagio, M. Ashari "RNN Based Rotor Flux and Speed Estimation of Induction Motor,", International Journal of Power Electronics and Drive System (IJPEDS), Vol. 1, No. 1, pp. 58-64, 2011.

[23] T. Belbekri, B. Bouchiba, I. K. Bousserhane, H. Becheri "Speed Sensorless Field-Oriented Control of Induction Motor with fuzzy luenberger observer," Electrotehnica Electronica Automatica (EEA), Vol. 66, No. 4, pp. 22-28, 2018.

[24] S. Yi, W. M. Utomo, G. H. Hwang, C. S. Kai, A. J. Lim Meng Siang, N. A. Zambri, Y. M. Y. Buswig, K. H. Law, S. G. Yi "Loss minimization DTC electric motor drive system Based on adaptive ANN strategy," International Journal of Power Electronics and Drive System (IJPEDS), Vol. 11, No. 2, pp. 618-624, 2020.

[25] H. Arabaci "An artificial neural network approach for sensorless speed estimation via rotor slot harmonics," Turkish Journal of Electrical Engineering \& Computer Sciences, vol. 22, pp. 1076-1084, 2014.

\section{BIOGRAPHIES OF AUTHORS}

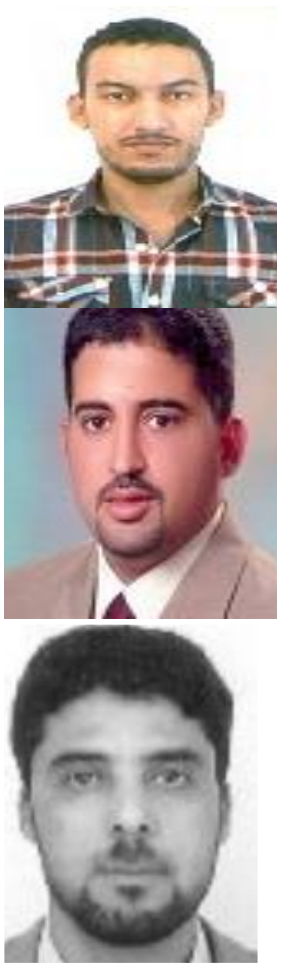

Tahar BELBEKRI borned in 1987 in Béchar (Algeria). He obtained the electrical engineering diploma from Béchar University, (Algeria) in 2010. The magister degree in Electrical Engineering from university of Tahri mohamed, (Algeria), in 2014. He's currently preparing his Ph.d. degree.

e-mail address: taharmoh87@yahoo.fr

Bousmaha BOUCHIBA, borned in Béchar (Algeria), in 1977, he obtained his electrical engineering diploma from Béchar University, (Algeria) in 1999. And a Master degree from the University Alexandria Egypt in 2006. He achieved the doctoral degree in electrical engineering from the University of SDB (Algeria), in 2011. Currently, He is Professor at the University of Tahri Mohamed Béchar (Algeria).

e-mail address: bouchiba_bousmaha@yahoo.fr

Ismail khalil BOUSSERHANE borned in 1976 in Béchar (Algeria). He obtained the electrical engineering diploma from Béchar University, (Algeria) in 2000. Magister degree in Electrical Engineering from the University USTO of Oran in 2003 and the Doctorate degree from the Electrical Engineering the University USTO of Oran in 2008, Algeria. Currently, He is professor of electrical engineering at University Tahri Mohamed of Béchar, Algeria.

e-mail address: bou_isma@yahoo.fr

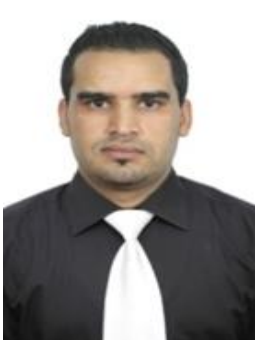

Houcine BECHERI borned in 1987 in Béchar (Algeria). He obtained the electrical engineering diploma from Béchar University, (Algeria) in 2010.The magister degree in Electrical Engineering from University of Tahri mohamed in Béchar (Algeria), in 2014. He received the doctorate degree in electrical engineering from the University of Tahri Mohamed of Béchar (Algeria), in 2018.

e-mail address: houcine.becheri@gmail.com 